\title{
Ethanolysis of Waste Cooking oils using KOH Catalyst
}

\author{
ABOULBABA ELADEB ${ }^{1 *}$, ABDELKARIM AYDI ${ }^{1}$ and IBRAHIM ALENEZI ${ }^{1}$ \\ 1'Department of Chemical and Materials Engineering, Northern Border University, Saudi Arabia. \\ ${ }^{*}$ Corresponding author E-mail: eladebboulbaba@gmail.com \\ http://dx.doi.org/10.13005/ojc/370611
}

(Received: November 10, 2021; Accepted: December 20, 2021)

\begin{abstract}
The transesterification of waste cooking oils (WCO) with ethanol was investigated by means of potassium hydroxide $(\mathrm{KOH})$ as catalyst. This work aimed to study the influences of catalyst concentration, temperature, ethanol to WCO molar ratio, reaction time, and stirring rate on the biodiesel conversion. Gas chromatography (GC) was used during the process of transesterification to determine the evolution of ethyl esters concentration with time. Biodiesel with maximum yield was obtained $(92.5 \%)$ when $2 \mathrm{wt} \% \mathrm{KOH}$, temperature of $75^{\circ} \mathrm{C}$, and ethanol/oil molar ratio of $11: 1$ were utilized.
\end{abstract}

Keywords: Waste cooking oil, Biodiesel, Transesterification, Ethanol, Optimization.

\section{INTRODUCTION}

Owing to the rapid industrialization and metropolitan expansion, energy demand continues to rise. Coal, petroleum, and natural gas are the main energy sources, and due to their non-renewable origin, these energy sources are depleting on a regular basis. Petroleum prices hit always new levels because of the strong reliance on petroleum as a primary source of fuel for transportation and power production'. However, the heavy use of these traditional energy supplies leads to the rise of the global warming, which must be treated by the exploitation of renewable energy sources ${ }^{2}$.

New options of energy such as biofuels should be adopted to overcome crisis generated by the fact of energy and environmental decline. These new substitutions must investigate renewable, sustainable and environmental-friendly sources ${ }^{3-9}$.
Biofuels, such as biodiesel, bio-ethanol, and biogas, are particularly appealing candidates for controlling the energy shortage because unused feedstocks are easily accessible ${ }^{10}$. Currently, biofuel production is growing worldwide and is expected to increase in the near future, using different conversion techniques, since petroleum stocks continue to be diminished ${ }^{11}$.

Biodiesel, among the various kinds of biofuels, is gaining popularity due to physiochemical characteristics, that allows it to be blended with diesel fuel ${ }^{12}$. Unlike usual fuel, biodiesel is renewable, reliable, biodegradable and clean ${ }^{13,14}$. In general, biodiesel is chemically fatty acid methyl esters (FAME) or fatty acid ethyl esters, which can be produced via chemical reaction between shortchain alcohol (methanol or ethanol) and oil in the presence of a suitable catalyst. Feedstocks for

This is an Open Access article licensed under a Creative Commons license: Attribution 4.0 International (CC- BY). Published by Oriental Scientific Publishing Company @ 2018 
biodiesel production include energy crops, animal fats, virgin oils, insects, and microalgae ${ }^{15}$. The cost of production is currently the most significant impediment to the commercialization of biodiesel. In this respect, utilizing waste materials for biodiesel production may be beneficial in lowering feedstock costs, making the process more cost-effective. Waste cooking oils, could be transformed to valuable biofuel, that could help to reduce emissions because WCO is discarded into the environment. Additionally, upgrading WCO to biodiesel would provide a valuable source of energy to the conventional energy grid $^{1,16}$. Furthermore, given the current state of environmental pollution ${ }^{17-22}$, clean and green procedures and methodologies are required.

Several researches examined various feedstocks in order to transform free fatty acids (FFA) into biodiesel. For example, Che et al., 2012, employed olive pomace oil to produce the fuel by acid esterification using sulfuric acid as a catalyst. Low alcohol to oil ratios resulted in a 50\% reduction in FFA values, whereas high alcohol used to oil ratios resulted in an over $80 \%$ reduction.

The greatest prevalent process to make biodiesel is transesterification. Transesterification occurs when lipids react with an alcohol to produce biodiesel as product with glycerol as co-product. Due to the irreversibility of the process, as indicated in equation 1, extra of alcohol should permanently be recommended to move the equilibrium to the product region. The reaction has a stoichiometry of $3: 1$. In fact, however, this is generally augmented to $6: 1$ in order to boost production.

Triglyceride $(\mathrm{TG})+3 \mathrm{ROH} \rightleftharpoons 3 \mathrm{R}^{\prime} \mathrm{CO}_{2} \mathrm{R}+$ Glycerol

Equations 2, 3 and 4 explain the transesterification mechanism. It is made up of 3 reversible and consecutive steps. Initially, triglycerides are transformed to diglycerides (equation 2) then diglycerides are converted to monoglycerides (equation 3 ). In the last step, monoglycerides is converted to glycerol (equation 3). Globally, with each glyceride produced at each step there is one ester molecule provided.

$$
\text { Triglyceride }(\mathrm{TG})+\mathrm{ROH} \rightleftharpoons \mathrm{R}^{\prime} \mathrm{COOR}+\text { Diglyceride }(\mathrm{DG})
$$

Diglyceride $(\mathrm{DG})+\mathrm{ROH} \rightleftharpoons \mathrm{R}^{\prime} \mathrm{COOR}+$ Monoglyceride $(\mathrm{MG})$
Monoglyceride $(\mathrm{MG})+\mathrm{ROH} \rightleftharpoons \mathrm{R}^{\prime} \mathrm{COOR}+$ Glycerol

Obviously, the presence of catalyst during the biodiesel production process is important due to its greatest impact on the conversion rate. For acidic transesterification (i.e $\mathrm{H}_{2} \mathrm{SO}_{4}$ as catalyst), it is required to use high temperatures for durations above $3 \mathrm{~h}$ of processing time. Unless, alkali-catalyst like potassium hydroxide take less time to achieve the final conversion at less temperatures ${ }^{23-26}$.

Methanol, ethanol, and butanol are short-chain alcohols often used for biodiesel production. Selection of the appropriate alcohol relies on its performance and cost related to the transesterification reaction. The main advantage of using ethanol instead of methanol, for example, biodiesel produced from ethanol has lower properties (cloud point and pour point) than biodiesel obtained from methanol as alcohol. In addition, ethanol is better to methanol, as solvent, since it has a far higher dissolving capacity for oils. Furthermore, it is possible to make ethanol by means of sustainable alternatives that make it more independent from conventional alcohols.

\section{MATERIALS AND METHODS}

The oil used in the biodiesel production process was the WCO collected from different restaurants located in Arar city, Northern Border Province, Saudi Arabia. The following chemicals were supplied by Sigma-Aldrich Chemical Company: 1,3-diolein $99 \%$, ethyl oleate $98 \%$, sodium ethoxide $95 \%$, ethanol $99.8 \%$, glycerol $99 \%$, 1-decanol $99.5 \%$, sulfuric acid $99.9 \%$. Mono-olein (99\%) and glyceryl trioleate (99\%) were purchased from Fluka Company. THF was supplied by VWR Company.

\section{Pretreatment of WCO}

Given the condition of the collected oil, it was necessary to pretreat it before its injection in the transesterification reactor. The first stage consists of filtering the mixture of WCO in order to eliminate existing food-particles and impurities. Then, the oil sample was heated at $110^{\circ} \mathrm{C}$ for almost 3 hours. The physiochemical properties of WCO were estimated (i.e density, kinematic viscosity, pour point, etc). Table 1 shows the main characteristics of the current WCO samples. 
Table 1: Physiochemical properties of WCO

\begin{tabular}{lcc}
\hline Propety & Unit & Biodiesel \\
\hline Density & $\mathrm{g} / \mathrm{cm}^{3}$ & 0.94 \\
Viscosity & $\mathrm{Mm}^{2} / \mathrm{s}$ & 32.67 \\
Pour poin & ${ }^{\circ} \mathrm{C}$ & 17 \\
Cloud point & ${ }^{\circ} \mathrm{C}$ & 22 \\
Acid value & $\mathrm{Mg} \mathrm{KOH} / \mathrm{g}$ & 3.64 \\
lodine value & $\mathrm{Mg} \mathrm{KOH} / \mathrm{g}$ & 9.75 \\
Saponification number & $\mathrm{Mg} \mathrm{KOH} / \mathrm{g}$ & 232.22 \\
\hline
\end{tabular}

\section{Transesterification process}

Transesterification of pretreated oil was accomplished in an oval batch-reactor with 4000 $\mathrm{mL}$ of size, equipped by feed inlet, thermostat, mechanical stirrer, condensation system, and sampling outlet. The experimental setup is shown in Figure 1.

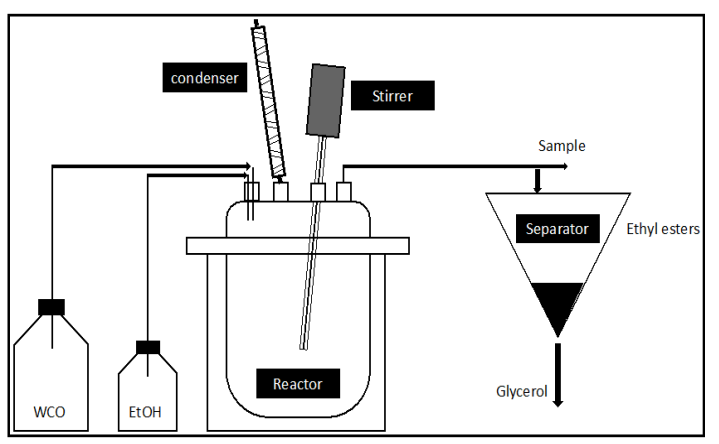

Fig. 1. Experimental setup of transesterification process

In order to remove existing humidity in the reactor, the temperature was, initially, set at $80^{\circ} \mathrm{C}$ for almost half-hour. $2400 \mathrm{~g}$ of WCO sample was fed inside the reactor after it reached the selected temperature which was $35^{\circ} \mathrm{C}, 50^{\circ} \mathrm{C}, 60^{\circ} \mathrm{C}, 75^{\circ} \mathrm{C}$, or $80^{\circ} \mathrm{C}$. Next, the alcohol-catalyst mixture was added to the reactional medium in respect to the quantities previously set for different tests. The mechanical stirrer was then associated to the experimental set up and the transesterification reaction started. For each experiment, $1 \mathrm{~cm}^{3}$ of sample was extracted at equal periods of 5 and 10 min for later GC analysis. During experiment, the reaction was retained at desired temperature for 120 minute. The ethanol/ oil molar ratio was ranging from 9:1 to $15: 1$, and the concentration of $\mathrm{KOH}$ catalyst varied from $0.5 \mathrm{wt} . \%$ to $3.5 \mathrm{wt}$ \% of the WCO.

When the reaction reached the equilibrium, two phases were distinguished. Biodiesel was produced in the upper phase while the lower phase was a mixture of glycerol, ethanol, and remaining
$\mathrm{KOH}$. Separation of both layers was conducted by sedimentation.

\section{Biodiesel analysis}

Analysis of all transesterification products; tri, di, mon-glycerides, ethyl esters, and glycerol was performed by means of gel permeation chromatography ${ }^{27}$. Biodiesel properties were measured as recommended by international standards procedures ${ }^{28-30}$.

\section{RESULTS AND DISCUSSION}

\section{Effect of catalyst concentration}

The catalyst concentration has a great effect on the biodiesel production rate. The impact of catalyst quantity is showed in Fig. 2. As shown, percentage of esters obtained increase with the increasing amount of catalyst concentration from 0.5-3.5 wt\%. The increase of catalyst concentration obviously improves ethyl esters conversion because of the high active surface area present in the transesterification process. At low concentrations, catalytic activity diminishes due to the insufficiency for a full production of ethyl esters.

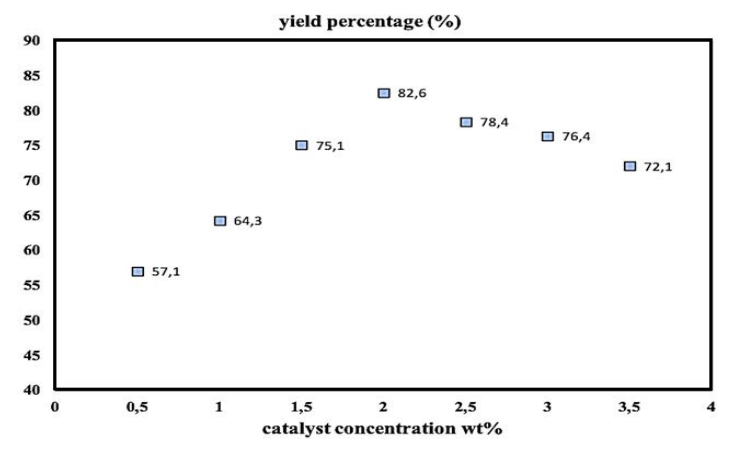

Fig. 2. Effect of catalyst concentration [reaction time $t=120$ $\min$, ethanol $/ \mathrm{WCO}=10: 1$, reaction temperature $\mathrm{T}=60^{\circ} \mathrm{C}$ ]

Increasing the $\mathrm{KOH}$-catalyst quantities from $0.5 \mathrm{wt} \%$ to $2 \mathrm{wt} \%$ increased considerably the biodiesel yield from $57.1 \%$ to $82,6 \%$. However, above this value (2 wt\%) the conversion reduced to reach $72.1 \%$ at $3.5 \mathrm{wt} \%$ catalyst load. These results might be justified since a soap phase was created in the reactional medium which made the biodiesel recovery not easier. As result, the viscosity of the medium increased due to emulsion formation. Emulsion did not happen when catalyst quantities are below $1.5 \mathrm{wt} \%$ and results showed low ethyl esters rates. 


\section{Effect of ethanol to oil molar ratio}

The ratio of alcohol to oil has also a high impact on the WCO conversion rate. Transesterification reaction is frequently conducted with an excess of alcohol to push the formation of ethyl esters. Stoichiometrically, the reaction requires only a 3:1 ratio, but according to the literature $^{31,32}$, it is impossible to shift the equilibrium below a rate of $5: 1$.

Thus, several tests were used out to assess the influence of WCO on ethanol molar ration on the biodiesel production. It was varied between 9:1 and 15:1 as recommended by several studies ${ }^{31-33}$. The temperature was $75^{\circ} \mathrm{C}$ and $\mathrm{KOH}$, at a concentration of $2 \mathrm{wt}$. percent, was carried out as a catalyst, based on the effects of catalyst load discussed previously. Fig. 3 shows the influence of oil to alcohol ration on the evolution of esters yield with the reaction time. As shown, the biodiesel yield increase with the rise of the molar ratio. The optimum yield $(92.5 \%)$ was obtained, after $2 \mathrm{~h}$ of transesterification process, for a molar ratio 11:1.

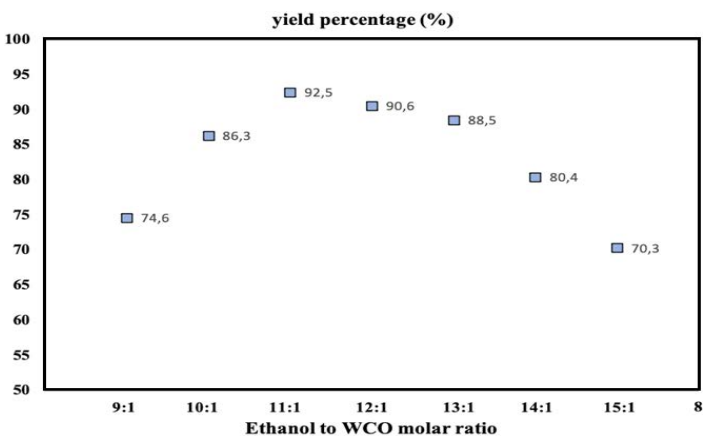

Fig. 3. Effect of ethanol to WCO molar ratio [reaction time $\mathbf{t}=\mathbf{1 2 0} \mathbf{m i n}, \mathrm{KOH}$ concentration $2 \mathrm{wt} \%$, reaction temperature $\mathrm{T}=75^{\circ} \mathrm{C}$ ]

However, an increase in the molar ratio to $15: 1$ would not result in an increase in yield, since the lower yield produced (70.3 percent). This reduction could be explained by the excess amount of ethanol present in the medium which made the separation between biodiesel and glycerol more difficult. As a result, remaining by-product in the ester phase leaded to foam formation and consequently decrease in the biodiesel yield.

\section{Effect of reaction temperature}

The temperature is one of the key factors that directly affect the biodiesel yield. At $75^{\circ} \mathrm{C}$, highest production of biodiesel was reached (92.5\%), as shown in Fig. 4. Based on the obtained results, increasing the temperature resulted in an increase in the biodiesel yield. Above $75^{\circ} \mathrm{C}$ production rate decreased, since the continuous vaporization of the ethanol leaded to the decreasing of ethanol amount in the reactional medium.

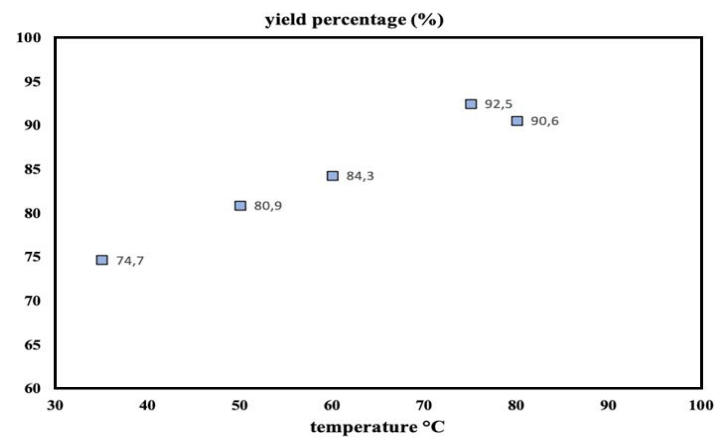

Fig. 4. Effect of transesterification temperature [reaction time $\mathrm{t}=120 \mathrm{~min}, \mathrm{KOH}$ concentration $2 \mathrm{wt} \%$, ethanol/WCO = 11:1]

Furthermore, during transesterification process, temperatures that exceed $75^{\circ} \mathrm{C}$ should be treated with extreme precaution. High temperatures have a negative effect on the biodiesel yield since it might speed up the soap formation before the equilibrium is reached. During experiments, this impact has, fortunately, not been detected. Therefore, $75^{\circ} \mathrm{C}$ was selected for WCO transesterification.

\section{Physiochemical properties of biodiesel}

The produced biodiesel in this study had properties in accordance to American standards and European standards. These physical properties are mentioned in Table 2.

Table 2 Physiochemical properties of biodiesel

\begin{tabular}{lcccc}
\hline Property & Unit & Biodiesel & ASTM D6751 & EU 14214 \\
\hline Density & $\mathrm{g} / \mathrm{cm}^{3}$ & 0.884 & 0.86 to 0.90 & 0.86 to 0.90 \\
Viscosity & $\mathrm{Mm}^{2} / \mathrm{s}$ & 5.67 & 1.9 to 6.0 & 3.5 to 5.0 \\
Pour point & ${ }^{\circ} \mathrm{C}$ & 1 & -15 to 10 & - \\
Cloud point & ${ }^{\circ} \mathrm{C}$ & 7 & -3 to 12 & - \\
Acid value & $\mathrm{Mg} \mathrm{KOH} / \mathrm{g}$ & 0.8 & $<312$ & 0.5 \\
Water content & $\%$ & & 0.05 & \\
Total glycerin & $\%$ & & 0.24 & \\
\hline
\end{tabular}

The density of biodiesel had a great impact on engine performance. Thus, this fuel property helps to break up the fuel-spray in the injector. Biodiesel had a density of $0.884 \mathrm{~g} / \mathrm{cm}^{3}$, which was within the range of the fuel standards. Viscosity is vital for the good combustion inside the engine. Very low or high viscosities causes a low in combustion of fuel air mixture which affect the proper functioning 
of engine. The biodiesel viscosity was $5.67 \mathrm{~mm}^{2} / \mathrm{s}$, slightly higher than the EU standards. The point at which crystals begin to form precipitate is known as the cloud point. Both the cloud point and pour point are indexes of low-temperature operability of the fuel. In this study, cloud point is found to be $7^{\circ} \mathrm{C}$ and pour point was $1^{\circ} \mathrm{C}$. The value of acid value in this study was $0.8 \mathrm{mg} \mathrm{KOH} / \mathrm{g}$ which is within the recommended standards. The acid value defines the amount of free fatty acid present in ethyl esters and its dependent to final purification method of the biodiesel.

\section{CONCLUSION}

According to previous studies and based on results obtained during this work, performing a process to generate biodiesel from WCO is reliable. The transesterification reaction was conducted in a lab-scale reactor and results showed that despite of being collected from different sources, WCO are an effective alternative to produce biodiesel. The reaction temperature, the catalyst concentration, the ethanol/WCO molar ration and the reaction time were the most important variables. Within the range of temperature employed, the optimum yield was reached at $75^{\circ} \mathrm{C}$. Low temperatures, however, could be an interesting way for industrial scale in order to save energy consumption. The $\mathrm{KOH}$ was the catalyst used in experiments and results showed that a concentration of $2 \mathrm{wt}$ \% provided the best ethyl esters yields. As indicated previously, ethanol to oil ratio is a key parameter on the efficiency of the transesterification process. For a molar ratio of 11:1, maximum yield was obtained.

\section{ACKNOWLEDGEMENT}

The authors gratefully acknowledge the approval and thesupport of this research study by the grant no. ENG-68582016-1-6-F from the Deanship of ScientificResearch at Northern Border University, Arar, K.S.A.

\section{Conflict of interest}

The author declare that we have no conflict of interest.

\section{REFERENCES}

1. Arshad, M.; Bano, I.; Khan, N.; Shahzad, M. I.; Younus, M.; Abbas, M.; Iqbal, M. Renewable and Sustainable Energy Reviews., 2018, 81, 1241-1246.

2. Canesin, E. A.; Oliveria, C. C. Electronic Journal of Biotechnology., 2014, 17, 39-45.

3. Asri, N. P.; Sari, D. A. P. Modern pplied Science., 2015, 9, 99.

4. Haigh, K. F.; Abidin, S. Z.; Saha, B.; Vladisavljevi, G. T. Progress in Colloid and Polymer Science., 2012, 139, 19-22.

5. Hiwot, T. Chemistry International., 2017, 3, 311-319.

6. Noiroj, K.; Intarapong, P.; Luengnaruemitchai, A.; Jai-In, S. Renewable Energy., 2009, 34, 1145-1150.

7. Saifuddin, N., Raziah, A.; Farah, H. Journal of Chemistry., 2009, 6, S485-S495.

8. Omar, W.; Nordin, N.; Mohamed, M.; Amin, N. 2009. Journal of Applied Sciences., 2009, 9, 3098-3103.

9. Wang, Y., Ou; S., Liu, P.; Xue, F.;Tang, S. 2006. Journal of Molecular Catalysis A: Chemical., 2006, 252, 107-112.

10. Che, F.; Sarantopoulos I.; Tsoutsos; T., Gekas, V. Biomass and Bioenergy., 2012.
36, 427-431.

11. Yusuf, N. N. A. N.; Kamarudin, S. K.; Yaakub, Z. Energy Conversion and Management., 2011, 52, 2741-2751.

12. Nisar, N.; Mehmood, S.; Nisar, H.; Jamil, S.; Ahmad, Z.; Ghani, N.; Renewable Energy., 2018, 117, 393-403.

13. Dong, S.; Zhu, M.; Dai, B. Green and Sustainable Chemistry., 2012, 2, 8-13.

14. Roy, M. M.; Wang, W.; Alawi, M. Energy Conversion and Management., 2014, 84, 164-173.

15. Yaakob, Z.; Mohammad, M.; Alherbawi, M.; Alam, Z.; Sopian, K. Renewable and Sustainable Energy Reviews., 2013, 18, 184-193.

16. Tangy, A.; Pulidindi, I. N.; Gedanken, A. Energy and Fuels., 2016, 30, 3151-3160.

17. Chham, A.; Khouya, E.; Oumam, M.; Abourriche, A. K.; Gmouh, S.; larzek, M.; Chemistry International., 2018, 4, 67-76.

18. Ghezali, S.; Mahdad-Benzerdjeb; A., Ameri M.; Bouyakoub, A. Z. Chemistry International., 2018, 4, 24-32.

19. Ibisi, N. E.; Asoluka, C. A. Chemistry International., 2018, 4, 52-59. 
20. Mansouri, S.; Elhammoudi, N.; Aboul-hrouz, S.; Mouiya, M.; Makouki, L.; Chham, A. Chemistry International., 2018, 4, 7-14.

21. Mehta, K. K.; Chandra, R. S.; Mehta, D. R.; Maisuria, M. M. Chemistry International., 2018, 4, 33-42.

22. Ramdani, N.; Benouis, K.; Lousdad, A.; Hamou, A.; Boufadi, M. Y. Chemistry International., 2018, 4, 102-108.

23. Schwad, A. W.; Bagby, M.O.; Freedman, B. Fuel., 1987, 66, 1372-1378.

24. Ma, F.; Hanna, M. A. Bioresource Technology., 1999, 70, 1-15.

25. Meher, L. C.; Sagar, D. V.; Naik, S. N. Sustainable Energy Review., 2006, 10, 248-268.

26. Van Gerpen, J. Fuel Process., 2005, 86, 1097-1107.
27. Fillières, R.; Bouchra, B. M.; Michel, D. Journal of the American Oil Chemists' Society., 1995, 72, 427-432.

28. Sivaramakrishnan, K.; Paramasivam R. Journal of Engineering and Applied Sciences., 2012, 7, 205-211.

29. Abdullah, N. H.; Hasan, S. H.; Yusoff, N. R. M. International Journal of Materials Science and Engineering., 2013, 1, 94-99.

30. ASTM D 6751-15b. ASTM International., 2011, 1-10.

31. Encinar, J. M.; Juan, F. G; Antonio, R. R. Industrial \& Engineering Chemistry Research., 2005, 44(15), 5491-5499.

32. Cetinkaya, M.; Karaosmanoglu, F. Energy Fuels., 2004, 18, 1888-95.

33. Idris, A. M. Egyptian Journal of Petroleum., 2015, 25(1), 21-31. 